\title{
INDEK KERENTANAN DAN AMPLIFIKASI TANAH AKIBAT GEMPA DI WILAYAH UNIVERSITAS MUHAMMADIYAH JEMBER
}

\author{
Vulnerability and Soil Amplification Index Due to Earthquake in The University Muhammadiyah \\ Jember
}

\author{
$\operatorname{Muhtar}^{1} \&$ Arief Alihudien ${ }^{2}$ \\ ${ }^{1}$ Jurusan Teknik Sipil Fakultas Teknik - Universitas Muhammadiyah Jember \\ ${ }^{2}$ Jurusan Teknik Sipil Fakultas Teknik - Universitas Muhammadiyah Jember \\ Alamat Korespondensi : Perum Taman Bambu B-01 Jember 68124 \\ Email : ${ }^{1)}$ muhtar.fitrah@gmail.com
}

\begin{abstract}
Natural phenomena of earthquakes until now could not be predicted and the exact time it happened. Earthquake danger can not be avoided but its impact can be reduced through assessment activities characteristic earthquakes in a region that will be applied in the selection of methods and policies for disaster risk management. Residential areas adjacent to the source of the earthquake is an earthquake-prone area so, therefore it is necessary strategic steps to protect the public and disaster mitigation measures are an attempt to reduce or minimize the impact of loss or damage that may be caused by the disaster. The study was conducted to provide information to the seismic vulnerability using multicriteria analysis of conditions in the region include University of Muhammadiyah Jember dominant period land values and the value of the amplification factor. The experiment was conducted using subsurface observation with mikrotremoR. From the results of geological studies research area is the basic constituent of igneous rocks such as tuff Argopuro. The results showed that the natural frequency of the soil and soil amplification is at 2,692 and 4,625 $\mathrm{Hz}$. whereas soil vulnerability index value is equal to 7,946.
\end{abstract}

Key Words : seismic, vulnerability, index

\begin{abstract}
Abstrak
Fenomena alam gempa bumi sampai saat ini belum bisa diprediksi dan waktu yang tepat itu terjadi . Bahaya gempa tidak dapat dihindari namun dampaknya dapat dikurangi melalui kegiatan penilaian gempa bumi karakteristik di daerah yang akan diterapkan dalam pemilihan metode dan kebijakan untuk manajemen risiko bencana. Daerah pemukiman yang berdekatan dengan sumber gempa adalah daerah rawan gempa sehingga, oleh karena itu langkah-langkah strategis yang diperlukan untuk melindungi tindakan publik dan mitigasi bencana merupakan upaya untuk mengurangi atau meminimalkan dampak kerugian atau kerusakan yang mungkin disebabkan oleh bencana. Penelitian ini dilakukan untuk memberikan informasi kepada kerentanan seismik menggunakan analisis multikriteria kondisi di kawasan ini mencakup Universitas Muhammadiyah Jember nilai tanah periode dominan dan nilai faktor amplifikasi . Penelitian dilakukan dengan menggunakan observasi bawah permukaan dengan mikrotremoR. Dari hasil daerah penelitian studi geologi adalah konstituen dasar batuan beku seperti tuf Argopuro . Hasil penelitian menunjukkan bahwa frekuensi alami amplifikasi tanah dan tanah di 2,692 dan $4.625 \mathrm{~Hz}$. sedangkan nilai indeks kerentanan tanah sama dengan 7946 .
\end{abstract}

Kata Kunci : seismik, kerentanan , indeks

\section{PENDAHULUAN}

Secara geografis, Indonesia terletak pada pertemuan tiga lempeng tektonik utama dunia, yaitu lempeng Australia, Eurasia, dan Pasifik. Lempeng Eurasia dan Australia bertumbukan di lepas pantai barat Pulau Sumatera, lepas pantai selatan Pulau
Jawa, lepas pantai Selatan Pulau Nusa Tenggara. Sedangkan lempeng Australia dan lempeng Pasifik terjadi tumbukan di sekitar Pulau Papua. Hal ini menyebabkan kawasan Indonesia rawan akan gempa bumi

Lempeng tektonik aktif Samudera HindiaAustralia terhadap lempeng Eurasia di sebelah 
Barat. Selain dipengaruhi secara aktif oleh gerak tektonika pada lajur tunjaman, wilayah ini dipengaruhi juga oleh gerak patahan aktif Sumatera yang Membentang dari Provinsi Aceh hingga Provinsi Lampung. Kondisi ini menyebabkan wilayah ini kerap dilanda gempabumi.

Gempa bumi dapat merusak bangunan. Terdapat empat faktor penyebab kerusakan bangunan yang diakibatkan gempa bumi, antara lain: magnitude gempa, jarak bangunan terhadap sumber gempa, kualitas bangunan dan karakteristik tanah dimana bangunan tersebut berdiri. Dari keempat penyebab tingkat kerusakan bangunan tersebut, ada dua hal yang bisa diupayakan untuk mengurangi jumlah korban akibat gempa bumi yaitu meningkatkan ualitas bangunan dan mengetahui atau memetakan karakteristik atau watak respon tanah terhadap getaran gempa bumi.

Dengan demikian, maka mengetahui tingkat kerentanan diperlukan sebagai langkah awal untuk mengurangi resiko bencana alam khususnya gempa bumi. Agar bisa menjadi upaya nyata pengurangan resiko bencana, perlu langkah lanjut berupa kebijakan Pimpinan Universitas Muhammadiyah untuk mengatur tata ruang. kampus dengan konstruksi yang sesuai dengan tingkat kerentanan tanah terhadap gempa yang terjadi.

Kajian ini diharapkan dapat menjawab permasalahan-permasalahan di bawah ini:

- Bagaimanan pengaruh gempa berdasarkan efek lokal, yakni: amplifikasi, dan fekuensi natural tanah

- Bagaimana nilai kerentanan tanah akibat gempa di wilayah Universitas Muhammadiyah Jember

Tujuan yang ingin dicapai dalam penelitian ini
- Mengetahui pengaruh gempa berdasarkan efek lokal, yakni: amplifikasi, dan fekuensi natural tanah

- Mengetahui nilai kerentanan tanah akibat gempa di wilayah Universitas Muhammadiyah Jember

\section{METODE PENELITIAN}

\section{Tempat dan Waktu Penelitian}

Penelitian dilaksanakan di Wilayah Universitas Muhammadiyah Jember dengan koordinat 113.71517 E 8.17474 S, pada bulan Juni 2014.

Penelitian kerentanann tanah akibat gempa di Wilayah Unmuh Jember dilakukan dalam beberapa tahapan sebagai berikut:

- Survei awal : untuk memperoleh gambaran kondisi

- Geologi aktual. Alat yang digunakan adalah peta geologi, kompas geologi, kamera dan GPS (Global Posioning System).

- Penentuan Titik Koordinat Pengukuran Mikrotremor

- $\quad$ Akuisisi data microtremor dilapangan di setiap titik yang dihasilkan dari desain pengukuran. Alat yang digunakan adalah microtremor tiga sensor, GPS dan kompas geologi.

- Pengolahan data dilakukan dengan menggunakan Softwae geophsy. Hasil analisis ini dibandingkan dan hasilnya dipilih sesuai dengan geologi yang ada.

- Interpretasi hasil pengolahan data. Hasil interpretasi ini berupa tingkat kerusakan jika terjadi gempa. adalah sebagai berikut:

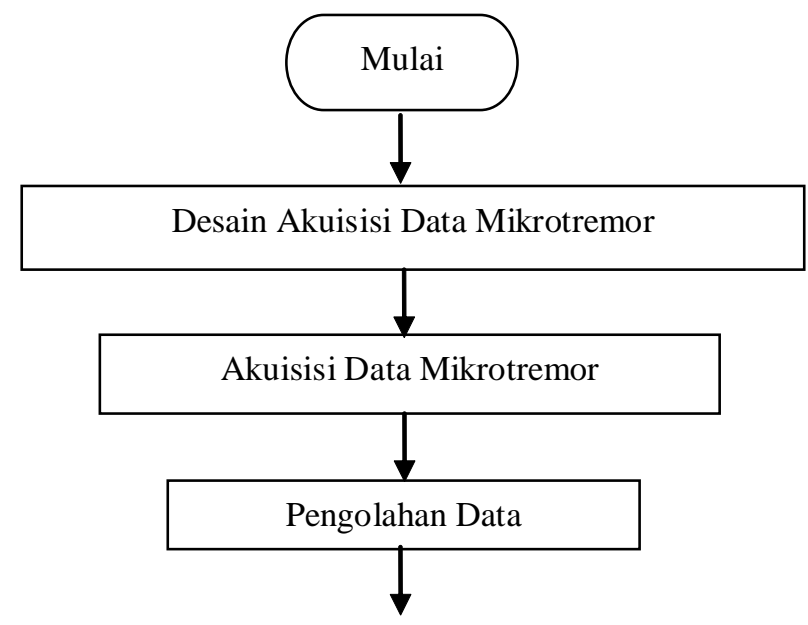




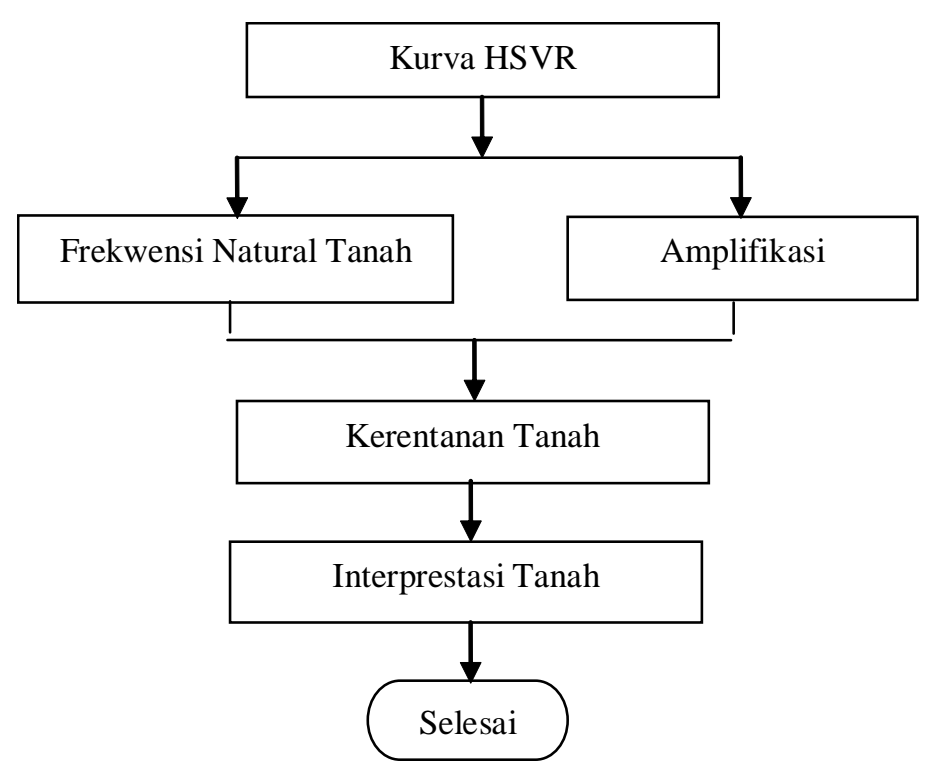

Gambar 1. Diagram alur penelitian

\section{HASIL DAN PEMBAHASAN}

\section{Tinjauan Geologi Wilayah Penelitian}

Keadaan geologi di Kabupaten Jember disusun oleh batuan Kuarter Tua, terutama pada daerah Gunung Argopuro. Menurut Widodo dkk. (2011) menyatakan bahwa proses pelapukan Breksi Argopuro yang berumur Kuarter Tua telah mencapai kedalaman lebih dari 20 meter dari muka tanah terdiri dari tanah residu dengan tebal 16 meter, tanah lapuk sedikit dengan tebal 4 meter dari batuan dasar. Dan menjelaskan bahwa G. Argopuro terletak di atas batuan dasar yang keras dengan SPT (Pengujian Penetrasi Standart) lebih dari 60 pukulan/kaki, dengan kemiringan lereng lebih dari 300 serta didominasi oleh material ukuran lempung-lanau, maka tanah residu volkanik Kuarter Tua G. Argopuro dalam keadaan kritis. Menurutnya, G. Argopuro juga dipengaruhi oleh terbentuknya endapan breksi volkanik hasil aliran lahar G. Merapi bulan Juni 2006, dan aktifitas endapan volkanisme G. Argopuro Panti Jember sudah berhenti lama dan endapan lahar yang sudah terbentuk langsung mengalami pelapukan.

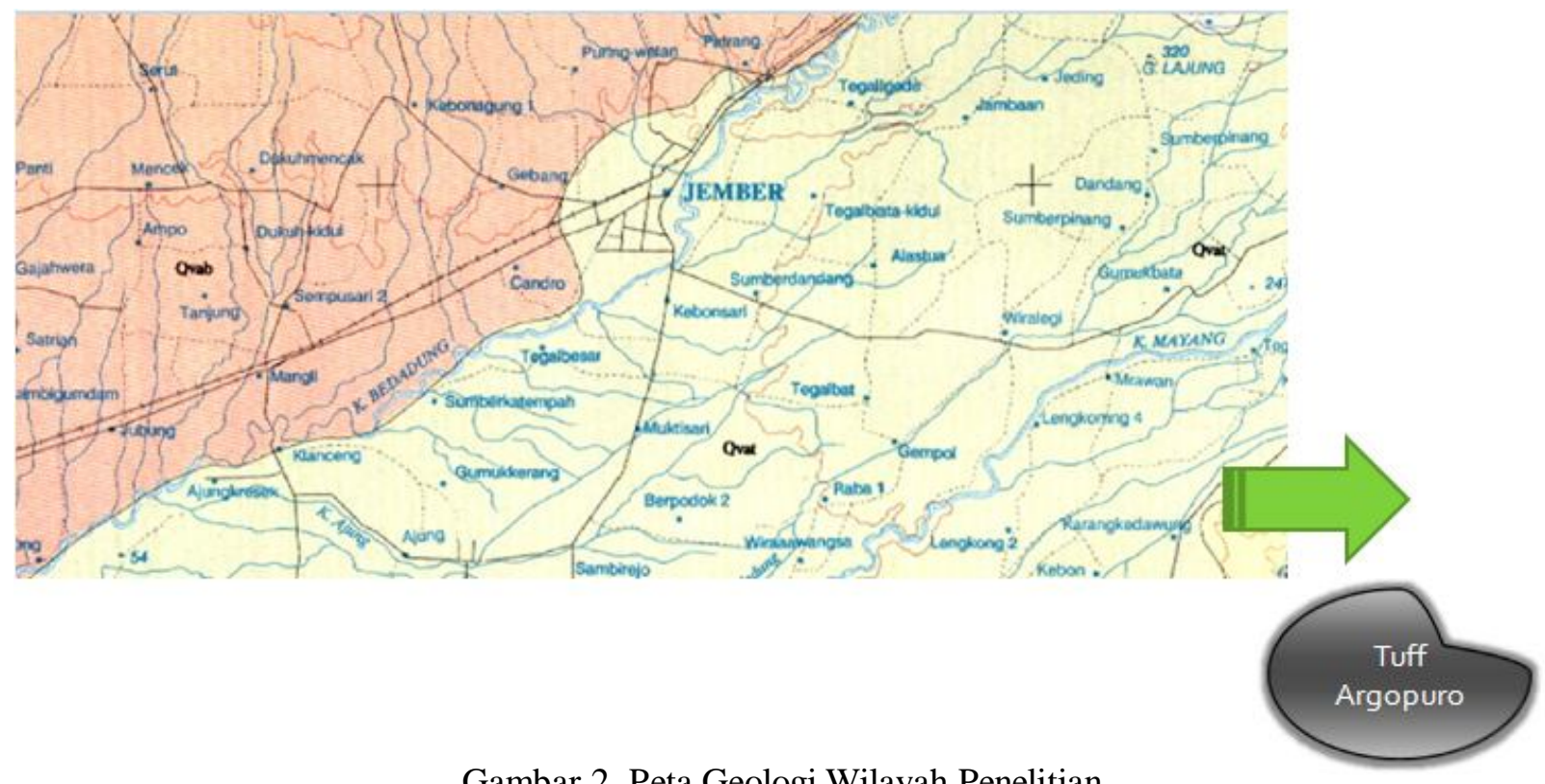

Gambar 2. Peta Geologi Wilayah Penelitian Frekwensi Natural, Amplifikasi, Indek
Kerentanan
Mikrotremor merupakan getaran tanah yang sangat kecil dan terus menerus yang bersumber dari berbagai macam getaran seperti, lalu lintas, 
angin, aktivitas manusia dan lain-lain (Kanai,1983). Mikrotremor dapat juga diartikan sebagai getaran harmonik alami tanah yang terjadi secara terus menerus, terjebak dilapisan sedimen permukaan, terpantulkan oleh adanya bidang batas lapisan dengan frekuensi yang tetap, disebabkan oleh getaran mikro di bawah permukaaan tanah dan kegiatan alam lainnya. Penelitian mikrotremor dapat mengetahui karakteristik lapisan tanah berdasarkan parameter periode dominannya/ frekwensi natural dan faktor penguatan gelombangnya (amplifikasi)Hasil pengukuran sinyal oleh mikrotremor disajikan dalam gambar 3 . Sedangkan sinyal tersebut dimodifikasi menjadi sesuai dengan gambar 4. Dengan menggunakan software geopsy maka didapat kurva HVSR seperti dalam Gambar 5. Dari kurva HVSR tersebut didapat nilai frekwensi natural tanah sebesar $2.692 \mathrm{~Hz}$, sedang nilai Amplifikasi nya adalah sebesar 4.625. berdasarkan table jenis lapisan endapan oleh kanai tanah endapan diwilayah Universitas Muhammadiyah Jember Jenis tanah I sedang tipe tanah adalah III. Berdasarkan klasifikasi tersebut maka menurut kanai adalah Batuan alluvial,dengan ketebalan $>5 \mathrm{~m}$. Terdiri dari dari sandy-gravel, sandy hard clay, loam, dan lain lain. Perkiraan Ketebalan sedimen permukaan masuk dalam kategori tebal, sekitar 10 - 30 meter.

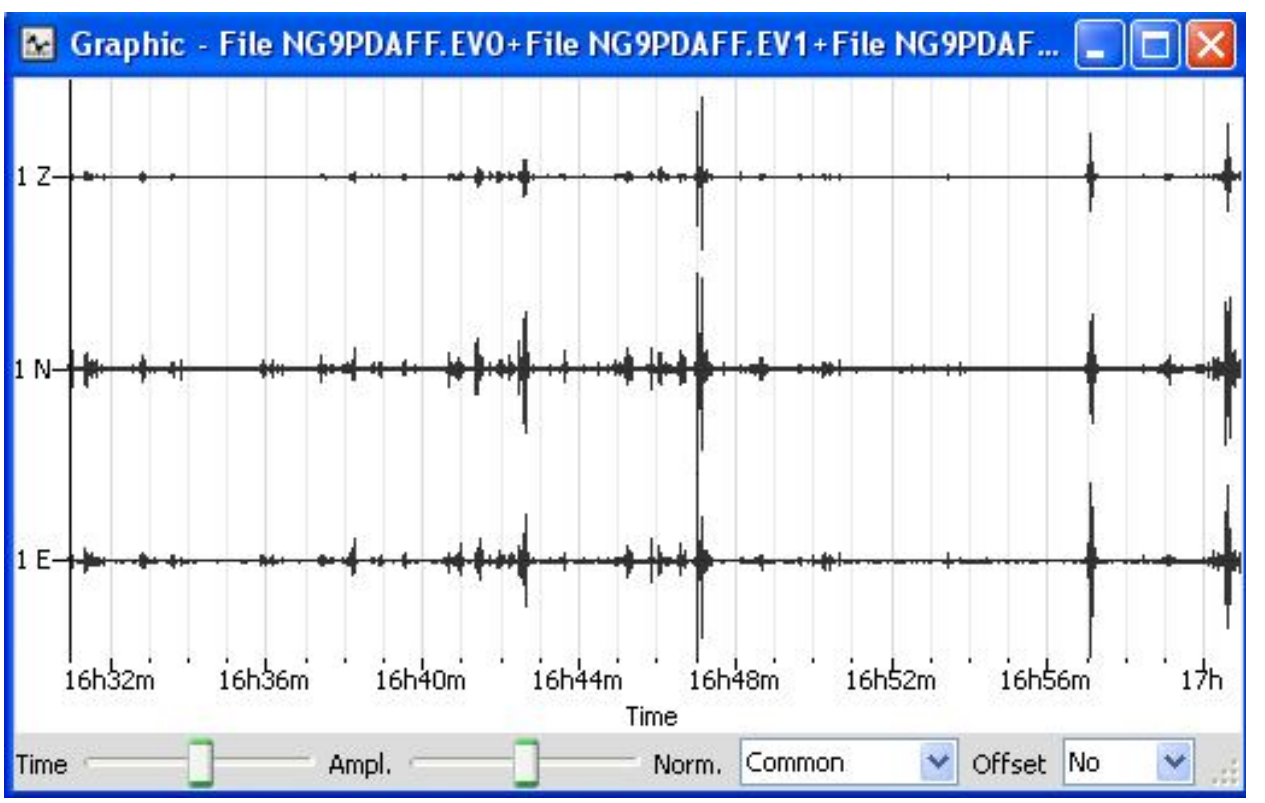

Gambar 3. Pembacaan sinyal oleh mikrotremor

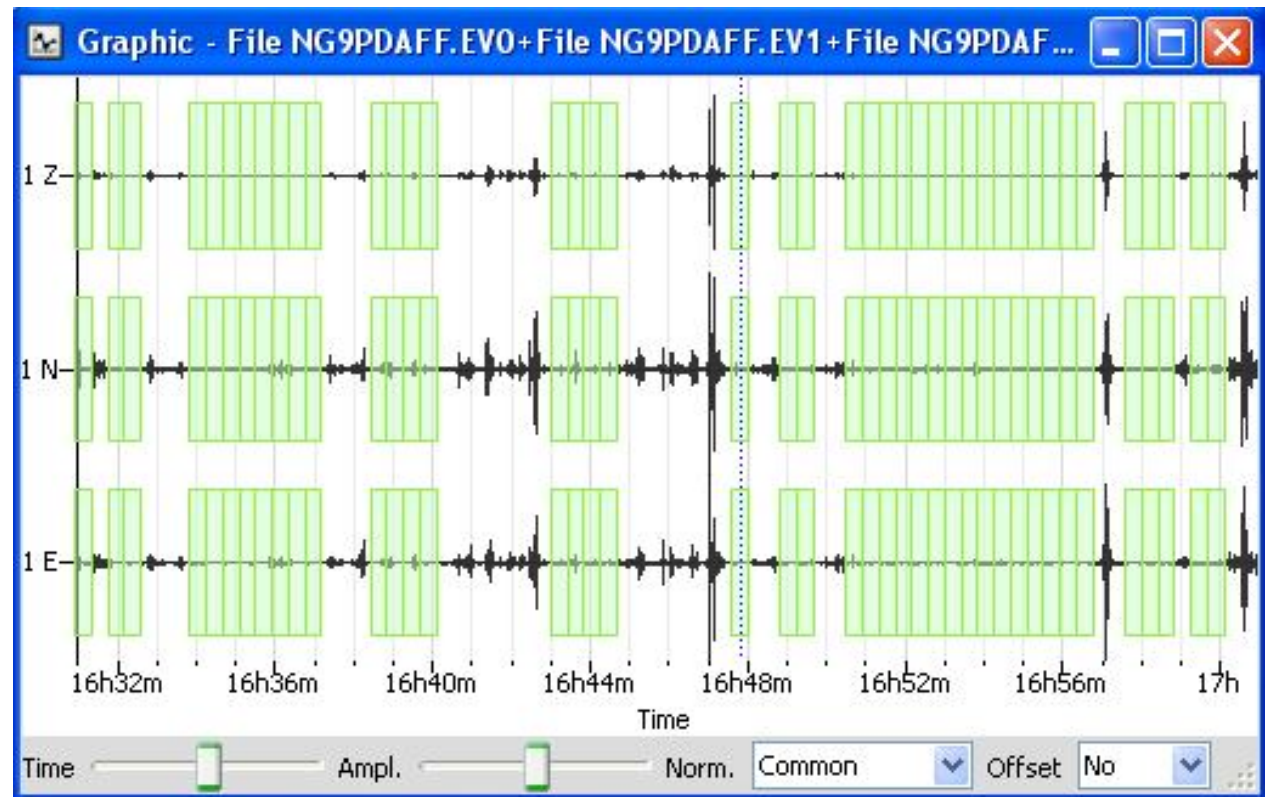

Gambar 4. Pembacaan sinyal oleh mikrotremor yang sudah direvisi 


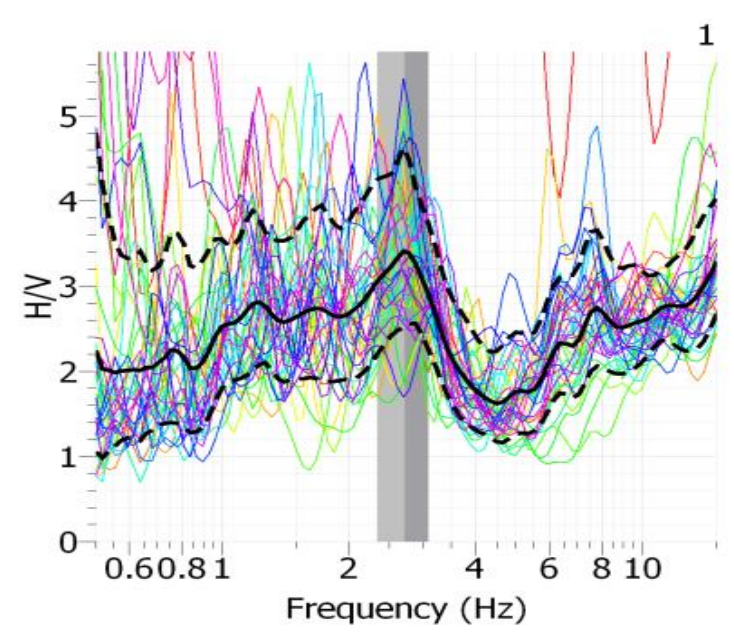

Gambar 5. Kurva HVSR

Tabel. 2. Nilai frekwensi natural dan ampilifikasi serta indek kerentanan tanah

\begin{tabular}{ccc}
\hline $\begin{array}{c}\text { Frekwensi } \\
\text { Natural tanah }\end{array}$ & Amplifikasi & $\begin{array}{c}\text { Indek } \\
\text { kerentanan }\end{array}$ \\
\hline $\begin{array}{c}\text { fo } \\
(\mathrm{Hz})\end{array}$ & Am & $\mathrm{Ks}$ \\
2.692 & 4.625 & 7.946 \\
\hline
\end{tabular}

\section{KESIMPULAN DAN SARAN}

\section{Kesimpulan}

Dari hasil penelitian dapat diambil beberapa kesimpulan sebagai berikut :

1. Batuan Penyusun base rock merupakan tuff argopuro

2. Nilai frekwensi natural tanah fo di wilayah Universitas Muhammadiyah sebesar 2.692 $\mathrm{Hz}$, perkiraan ketebalan tanah endapan diperkirakan $10 \mathrm{~s} / \mathrm{d} 30 \mathrm{~m}$,

3. Amplifikasi (Am) di wilayah Universitas Muhammadiyah sebesar 4.625

4. Indek kerentanan tanah akibat gempa di wilayah Universitas Muhammadiyah sebesar 7.946

\section{Saran}

Adapun saran terhadap peneltian ini adalah pengamatan menggunakan mikrotremor merupakan pengamatan fisis yang dilakukan diatas permukaan tanah oleh karena itu data yang didapat perlu di validasi dengan pengamatan menggunakan bor dalam. Oleh karena itu penelitian ini masih langkah awal dan nantinya akan dilanjutkan kedalam penelitian lebih lanjut.

\section{DAFTAR PUSTAKA}

Marjiyono. 2010. Estimasi Karakteristik Dinamika Tanah Dari Data Mikrotremor Wilayah Bandung. Thesis ITB. Bandung.

Nakamura, Y., 1989. A Method For Dynamic Characteristics Estimation of Subsurface Quarterly Reports Of The Railway Technical Research Institute. Tokyo

Nakamura, Y., 2000. Clear Indentification of Fundamental Idea of Nakamura's Technique and Its Application. Tokyo University. Japan.

Parwatiningtyas, D.,2008. "Perbandingan Karakteristik Lapisan Bawah Permukaan Berdasarkan Analisis Gelombang Mikrotremor Dan Data Bor".Jurnal Ilmiah Universitas Indraprasta PGRI.

Prager, E. J., 2006. Furious Earth : The Science and Nature of Earthquakes, Volcanoes and Tsunamis. Bandung: Penerbit Buku Pakar Raya.

Ramdani, R. N., 2011. Pemetaan Mikrozonasi Gempabumi Di Daerah Jepara Jawa Tengah Dengan Metoda HVSR. Universitas Pendidikan Indonesia. Bandung.

Sheriff, R. E., dan Geldart, L. P., 1995. Exploration Seismology 2nd Edition. Cambridge University Press : New York. USA. Wiradisastra. 2002. Geomorfologi dan Analisis Landskap. Institut Pertanian Bogor. Bogor. 